\title{
Prevalence and risk factors of testicular microlithiasis in patients with hypospadias: a retrospective study
}

Michiko Nakamura' ${ }^{1}$ Kimihiko Moriya ${ }^{1 *} \mathbb{D}$, Yoko Nishimura', Mutsumi Nishida ${ }^{2,3}$, Yusuke Kudo $^{2,3}$, Yukiko Kanno ${ }^{1}$, Takeya Kitta', Masafumi Kon ${ }^{1}$ and Nobuo Shinohara ${ }^{1}$

\begin{abstract}
Background: It has been described that the incidence of testicular microlithiasis is high in several congenital disorders which may be associated with testicular impairment and infertility. Several reports have shown that a prepubertal or pubertal hormonal abnormality in the pituitary-gonadal axis was identified in some patients with hypospadias that is one of the most common disorders of sex development. However, exact prevalence or risk factors of testicular microlithiasis in patients with hypospadias have not reported so far. In the present study, to clarify the prevalence and risk factors of testicular microlithiasis in patients with hypospadias, a retrospective chart review was performed.
\end{abstract}

Methods: Children with hypospadias who underwent testicular ultrasonography between January 2010 and April 2016 were enrolled in the present study. Severity of hypospadias was divided into mild and severe. The prevalence and risk factors of testicular microlithiasis or classic testicular microlithiasis were examined.

Results: Of 121 children, mild and severe hypospadias were identified in 66 and 55, respectively. Sixteen children had undescended testis. Median age at ultrasonography evaluation was 1.7 years old. Testicular microlithiasis and classic testicular microlithiasis were documented in 17 children (14.0\%) and $8(6.6 \%)$, respectively. Logistic regression analysis revealed that presence of undescended testis was only a significant factor for testicular microlithiasis and classic testicular microlithiasis. The prevalence of testicular microlithiasis or classic testicular microlithiasis was significantly higher in children with undescended testis compared to those without undescended testis (testicular microlithiasis; $43.8 \%$ versus $9.5 \%$ ( $p=0.002)$, classic testicular microlithiasis; $37.5 \%$ versus $1.9 \%(p<0.001)$.

Conclusions: The current study demonstrated that the presence of undescended testis was only a significant risk factor for testicular microlithiasis or classic testicular microlithiasis in patients with hypospadias. As co-existing undescended testis has been reported as a risk factor for testicular dysfunction among patients with hypospadias, the current findings suggest that testicular microlithiasis in children with hypospadias may be associated with impaired testicular function. Conversely, patients with isolated HS seem to have lower risks for testicular impairment. Further investigation with longer follow-up will be needed to clarify these findings.

Keywords: Testicular microlithiasis, Hypospadias, Undescended testis, Ultrasonography

\footnotetext{
* Correspondence: k-moriya@med.hokudai.ac.jp

${ }^{1}$ Department of Renal and Genitourinary Surgery, Hokkaido University

Graduate School of Medicine, North-15, West-7, Kita-Ku, Sapporo 060-8638,

Japan

Full list of author information is available at the end of the article
}

(c) The Author(s). 2018 Open Access This article is distributed under the terms of the Creative Commons Attribution 4.0 International License (http://creativecommons.org/licenses/by/4.0/), which permits unrestricted use, distribution, and

reproduction in any medium, provided you give appropriate credit to the original author(s) and the source, provide a link to the Creative Commons license, and indicate if changes were made. The Creative Commons Public Domain Dedication waiver (http://creativecommons.org/publicdomain/zero/1.0/) applies to the data made available in this article, unless otherwise stated. 


\section{Background}

Hypospadias (HS) is one of the most common disorders of sex development, occurring in 0.52 to 8.2 of every 1000 live male births $[1,2]$. Although the exact etiology of HS is unknown in the majority of patients, a multifactorial etiology including genetic, endocrine and environmental factors is considered to be involved in the genesis of this disorder [3]. HS is also considered as one of the symptoms of testicular dysgenesis syndrome (TDS), which was proposed in 2001 [4]. It has been speculated that impaired development of fetal testes could lead to increased risk of undescended testis (UDT), HS, decreased spermatogenesis and testicular cancer [5]. Several reports have shown that a prepubertal or pubertal hormonal abnormality in the pituitary-gonadal axis was identified in some patients with HS from endocrinological point of view [6-10], which is compatible with the concept of TDS.

Testicular microlithiasis (TM) is characterized by multiple, small, uniform-appearing echogenic foci of less than $3 \mathrm{~mm}$ without acoustic shadowing in the seminiferous tubules, which may be indicative of degeneration of the testicular parenchyma $[11,12]$. Several theories about the origin or causes of TM have been reported, however, the exact etiology of TM still remains unclear [13]. Previous studies have reported an association between TM and testicular germ cell tumors and/or carcinoma in situ $[14,15]$. In addition, an association between TM and infertility has been reported [15]. Although real impact of TM in children is still a matter of debate, it has been described in previous reports that the incidence of TM is high in some congenital disorders, such as UDT, Down's syndrome, Klinefelter syndrome, McCune-Albright syndrome and Peuzt-Jeghers syndrome, which may be associated with testicular impairment and infertility [16-20].

Based on these previous reports, TM may be a sign of a future endocrinological abnormality in the pituitary-gonadal axis [6-10] or testicular malignancy among patients with HS as a phenotype of TDS. Therefore, we performed testicular ultrasonography (US) for the screening of testicular abnormalities in patients with HS. Because several reports demonstrated that patients with associated genital anomaly, including UDT, were at higher risk for impaired testicular function $[6,9,21]$, we speculated that TM may be identified at a higher rate in such patients. However, the exact prevalence of and TM in patients with HS has not been reported so far.

In the present study, we retrospectively examined the prevalence and the risk factors of TM among children with HS.

\section{Methods}

Medical charts of children who visited our hospital for the management or follow-up of HS between January 2010 and April 2016 were retrospectively reviewed. Among them, patients who were born between December 1999 and August 2015, and who underwent on testicular US were included in the present study. Patients with obvious disorders of sex development or with chromosomal abnormalities were excluded. To evaluate and define risk factors of TM in children with HS, the following parameters were assessed with respect to their relation to the prevalence of TM: birth weight, presence of UDT, severity of HS, testosterone administration before HS surgery, and age at US. Severity of HS was divided into mild and severe based on the necessity of transecting urethral plate for correction of chordee deformity according to Koyanagi et al. [22].

TM was defined as 1 or more foci measuring 1 to $3 \mathrm{~mm}$ in diameter on testicular US. TM was classified as limited TM (LTM, echogenic foci < 5 /field) or classic TM (CTM, echogenic foci $\geq 5$ /field) as reported by Goede et al. [23] (Fig. 1). Among patients with TM, children with CTM in at least one testis were diagnosed with CTM, whereas others were classified as having LTM.

All US evaluation was performed without sedation by sonographers. US evaluations were performed using a PLT-1204BT, a linear probe, 7.2-18 MHz equipped with Aplio $^{\mathrm{Tm}}$ XG/500 (Toshiba Medical Systems Corp., Tochigi, Japan), a EUP-65, a linear probe 6-14 MHz equipped with HI VISION Avius (Hitachi- Medical, Tokyo, Japan), and a ML6-15, a linear probe 6-15 MHz equipped with Logiq
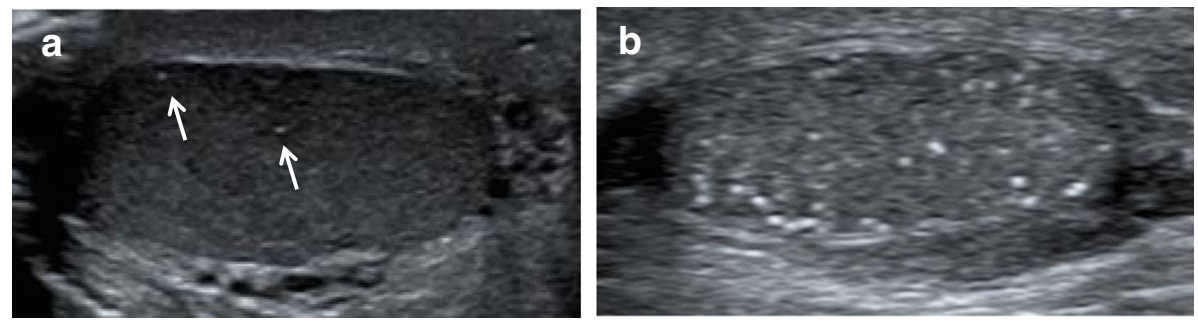

Fig. 1 Representative pictures of LTM and CTM. a Limited testicular microlithiasis (arrows) in an 11-year-old boy with hypospadias and undescended testis. Ultrasonography of right testis showed 2 small, uniform-appearing echogenic foci without acoustic shadowing. His left testis also displayed 4 echogenic foci per field. b Classic testicular microlithiasis in a 1-year-old boy with hypospadias. Ultrasonography of left testis demonstrated more than 5 echogenic foci per field. Right testis also displayed more than 5 echogenic foci per field 
E9 (GE Healthcare, Amersham, UK). If multiple examinations were performed during follow-up, the final assessment findings were evaluated for prevalence and risk factors of TM.

$\mathrm{JMP}^{\circ}$ pro version 12 was used for all statistical analyses. Statistical analyses were performed using logistic regression analysis and Fisher's exact test. $P<0.05$ was considered significant.

\section{Results}

Among 219 children who visited during the study period, 121 children (55.3\%) were included in the current study. Patient characteristics are shown in Table 1. Median birth weight was $2456 \mathrm{~g}$, and the number of children with low birth weight (less than $2500 \mathrm{~g}$ ) was 62. Mild and severe HS were identified in 66 and 55 children, respectively. UDT was observed in 16 patients (bilateral in 11, unilateral in 5). Of those, 4 had mild HS, and 12 had severe HS. Regarding co-existing congenital anomaly, inguinal hernia and heart anomaly were observed in 13 and 8, respectively. Testosterone administration before HS surgery was performed in 94 children. Median age at testicular US was 1.7 years old.

\section{Prevalence of TM and CTM}

TM and CTM were documented in 17 children (14.0\%) and in 8 children $(6.6 \%)$, respectively. TM was identified unilaterally in 7 , and bilaterally in 10 . Among 8 children with CTM, bilateral CTM was identified in 5. In the remaining 3 children, unilateral CTM alone was detected in 1 , and CTM on one side and LTM on the other side in 2. No testicular tumors were detected on US in any children.

\section{Risk factors of TM and CTM}

Univariate analysis demonstrated that the severe type of HS and presence of UDT were risk factors for TM. On multivariate analyses, presence of UDT was only a risk

Table 1 Patient characteristics

\begin{tabular}{|c|c|c|}
\hline & $n=121$ & range \\
\hline $\begin{array}{l}\text { Birth weight } \\
(\mathrm{g}, \text { median } \pm \mathrm{SD})\end{array}$ & $2456 \pm 834$ (unknown 1) & $(472-4048)$ \\
\hline $\begin{array}{l}\text { Low birth weight } \\
(<2500 \mathrm{~g})(\mathrm{pts})\end{array}$ & 62 & \\
\hline Type of HS (pts) & mild: 66 / severe: 55 & \\
\hline UDT (pts) & 16 (unilateral: 5 / bilateral: 11) & \\
\hline \multirow{2}{*}{$\begin{array}{l}\text { Testosterone } \\
\text { administration } \\
\text { before surgery (pts) }\end{array}$} & yes: 94, no: 20 (unknown 7) & \\
\hline & $\begin{array}{l}\text { topical: } 67 \text { / systemic: } \\
10 \text { / topical+systemic: } 17\end{array}$ & \\
\hline $\begin{array}{l}\text { Age at USG } \\
\text { (yrs, median } \pm S D)\end{array}$ & $1.7 \pm 4.0$ & $(0.5-18.2)$ \\
\hline $\begin{array}{l}\text { TM (pts) } \\
\text { (LTM / CTM) }\end{array}$ & $\begin{array}{c}17 \\
(9 / 8)\end{array}$ & \\
\hline
\end{tabular}

factor for TM $(p=0.006)$ (Table 2). Regarding CTM, presence of UDT was only a risk factor on univariate analysis $(p<0.001)$ (Table 3). The incidence of TM or CTM was significantly higher in children with UDT compared with those without UDT (TM; 43.8\% versus 9.5\% $(p=0.002)$, CTM; $37.5 \%$ versus $1.9 \%(p<0.001))$ (Table 4$)$.

\section{Side of TM and UDT (Table 5)}

In 11 children with bilateral UDT, unilateral and bilateral TM were observed in 1 and 4, respectively. Among them, CTM in at least one side was identified in 4. Of 5 with unilateral UDT, TM was identified in 2 (both with bilateral CTM). Among 105 children without UDT, unilateral and bilateral TM were observed in 6 and 4, respectively. Of those, CTM in at least one side was observed only in 2 .

\section{Discussion}

To our knowledge, the current study represented the first report on the prevalence of TM in children with HS. TM and CTM were identified in 14.0 and 6.6\%, respectively, of children with HS. Presence of UDT was only a risk factor for TM and CTM.

Previous studies have shown that TM is associated with several conditions, including impaired spermatogenesis, testicular cancer and carcinoma in situ [14, 15]. In asymptomatic adults, the rate of CTM varies from 0.6 to $9 \%[24,25]$. Recent studies revealed that the prevalence of TM and CTM in asymptomatic boys was 4.2 and $2.4 \%$ respectively, and increased with age [23]. The prevalence of TM $(14.0 \%)$ and CTM (6.6\%) in children with $\mathrm{HS}$ in the current study seems to be relatively higher compared with that in asymptomatic boys in the previous reports. Although the etiology of HS is considered to be multifactorial, the concept of TDS, which suggests that impaired development of fetal testes could lead to increased risk of HS, has been proposed as one of the causes of HS. Drut et al. proposed that TM may be related with Sertoli cell dysfunction and abnormal embryogenesis during the early stages of testicular development [12]. Wohlfahrt-Veje et al. reported that dysgenetic testes often have an irregular US pattern in which TM may also be visible [5]. The reason for the relatively high prevalence of TM may be due to that children who have such embryological causes of testis anomaly could have been included in the present study.

We demonstrated that the presence of UDT was only a risk factor for TM and CTM. There are several reports of prepubertal or pubertal hormonal abnormalities of the pituitary-gonadal axis in some patients with HS [6-10]. In addition, there are several reports on patients with both HS and UDT, which is a risk factor of TM and CTM as demonstrated in our study, who were at a higher risk for decreased testicular function or impaired spermatogenesis 
Table 2 Risk factors for TM

\begin{tabular}{|c|c|c|c|c|}
\hline & \multicolumn{2}{|l|}{ Univariate analysis } & \multicolumn{2}{|l|}{ Multivariate analysis } \\
\hline & Odds ratio ( $95 \%$ confidence interval) & $p$ value & Odds ratio ( $95 \%$ confidence interval) & $p$-value \\
\hline Birth weight ( $g$, median $\pm S D$ ) & $0.44(0.04-4.09)$ & n.s. & & \\
\hline Low birth weight (<2500 g) & $0.84(0.68-4.09)$ & n.s. & & \\
\hline Severe type of HS & $3.40(1.17-11.35)$ & $0.024^{*}$ & $2.48(0.79-8.65)$ & n.s. \\
\hline UDT & $7.39(2.23-24.55)$ & $0.001^{*}$ & $5.8(1.68-19.95)$ & $0.006^{*}$ \\
\hline Testosterone administration & $1.57(0.39-10.59)$ & n.s. & & \\
\hline Age at USG & $0.28(0.04-2.52)$ & n.s. & & \\
\hline
\end{tabular}
${ }^{\circ} p<0.05$

[6, 21]. A number of reports have demonstrated the relationship between TM and impaired spermatogenesis [26-28], although this issue is still controversial [29]. Accordingly, TM in children with HS may be associated with decreased testicular function and/or impaired spermatogenesis. To determine the relationship between TM and testicular function/spermatogenesis in patients with HS, further follow-up with endocrinological evaluations until puberty is necessary.

While the prevalence of TM in patients with HS and without UDT (9.5\%) in the current study was slightly higher compared to that in asymptomatic boys (4.2\%) reported in the previous literature [23], the prevalence of CTM (1.9\%) was almost similar to that in asymptomatic boys (2.4\%). Accordingly, patients with isolated HS seem to have lower risks for testicular impairment. On the contrary, although the presence of UDT in patients with HS was demonstrated as a risk factor for TM in the current study or impaired semen quality in the previous report [21], there has been no comparative study focusing on risk of TM or testicular dysfunction between patients with isolated UDT and those with HS and UDT. To clarify the impact of HS in patients with UDT in terms of the risk of TM or testicular dysfunction, additional studies are necessary.

Previous studies reported that the prevalence of primary testicular tumors in patients with TM ranged from 15 to $45 \%[15,29]$. Thus, there was some concern that TM may lead to testicular cancer at the end of the 1990's. However, two studies revealed that the rate of

Table 3 Risk factors for CTM

\begin{tabular}{lcc}
\hline & Univariate analysis & \\
\cline { 2 - 3 } & $\begin{array}{l}\text { Odds ratio } \\
\text { (95\% confidence interval) }\end{array}$ & $p$-value \\
\hline Birth weight (g, median \pm SD) & $4.26(0.20-85.70)$ & n.s. \\
Low birth weight $(<2500 \mathrm{~g})$ & $1.61(0.38-8.14)$ & n.s. \\
Severe type of HS & $3.92(0.86-27.53)$ & n.s. \\
UDT & $30.90(6.23-231.37)$ & $<0.001^{*}$ \\
Age at USG & $0.19(0.01-3.62)$ & n.s. \\
\hline${ }^{*} p<0.05$ & &
\end{tabular}

TM in the asymptomatic population ranged from 2.4 to $5.6 \%[24,25]$, which is much higher than the prevalence of the lifetime risk of testicular cancer in the general population. Nowadays, it is recognized that TM in adults without known risk factors, such as previous testicular cancer, a history of UDT or testicular atrophy, seems to be a benign condition $[19,24,25,30]$. Regarding TM detected in childhood, Suominen et al. found 15 patients with neoplasms among 421 pediatric patients (3.6\%) by systematic review [31]. They described that TM should be considered a benign condition even in the pediatric age group, but the fact that TM is associated with testicular malignancy $(<5 \%)$ cannot be ignored. Although the concept of TDS included symptoms of HS, UDT and testicular cancer [5], as far as we know, there is no report demonstrating that the prevalence of testicular tumors is higher in patients with HS. Although UDT is well-known as a risk factor for testicular malignancy [32], it is obscure whether UDT is also a risk factor for testicular malignancy among patients with HS. Longer follow-up will clarify the exact associations among testicular malignancy, TM and/or UDT in children with HS.

There is some controversy regarding the method and duration of follow-up in patients with TM. In the guidelines produced by the European Society of Urogenital Radiology, the consensus opinion is that the presence of TM alone in the absence of other risk factors is not an indication for regular follow-up in adults [19]. However, this guideline did not mentioned children with HS. At this time, we believe that the follow-up protocol for patients with HS and TM should be determined based on the presence or absence of UDT because the exact risk for testicular malignancy in patients with HS alone remains obscure.

Several limitations of the present study should be addressed. First, this study was conducted in a retrospective

Table 4 Prevalence of TM and CTM

\begin{tabular}{lllc}
\hline & UDT $(+)$ & UDT $(-)$ & $p$-value \\
\hline Prevalence of TM & $43.8 \%(7 / 16)$ & $9.5 \%(10 / 105)$ & 0.002 \\
Prevalence of CTM & $37.5 \%(6 / 16)$ & $1.9 \%(2 / 105)$ & $<0.001$ \\
\hline
\end{tabular}


Table 5 Sides of testicular microlithiasis and undescended testis

\begin{tabular}{lccc}
\hline & Bilateral UDT & \multicolumn{2}{c}{ Unilateral UDT } \\
$n=11$ & $n=5$ & $\begin{array}{c}\text { Without UDT } \\
n=105\end{array}$ \\
\hline Unilateral TM & 1 & 0 & 6 \\
CTM & 1 & 0 & 0 \\
LTM & 0 & 0 & 6 \\
Bilateral TM & 4 & 2 & 4 \\
Bilateral CTM: & 2 & 2 & 1 \\
CTM and LTM & 1 & 0 & 1 \\
Bilateral LTM & 1 & 0 & 2 \\
\hline
\end{tabular}

nature and relatively small number of children. Second, there was no control group such as Japanese boys who had no genital disease or isolated UDT. Third, evaluation of chromosomal abnormalities was not performed in all children. Fourth, as children included in the current study were relatively young and because TM sometimes appears later in childhood [23], the true prevalence of TM in patients with HS may be higher than the prevalence in this study. Fifth, as endocrinological examination or semen analysis was not performed in the current study, testicular function could not be compared between patients with and without TM.

\section{Conclusions}

TM and CTM were identified in roughly 14.0 and $6.6 \%$ of children with HS, respectively. The prevalence of TM and CTM was significantly higher in patients with UDT. As UDT among children with HS has been reported as a risk factor for endocrinological abnormality and/or impaired spermatogenesis, these findings suggest that TM in children with HS may be associated with impaired testicular function. In addition, the prevalence of CTM in patients with isolated HS was almost equal to the previously reported prevalence in asymptomatic boys. Therefore, patients with isolated HS seem to have lower risks for testicular impairment. Further investigation with longer follow-up will be needed to clarify these findings.

\section{Abbreviations}

CTM: Classic testicular microlithiasis; HS: Hypospadias; LTM: Limited testicular microlithiasis; TDS: Testicular dysgenesis syndrome; TM: Testicular microlithiasis; UDT: Undescended testis; USG: Ultrasonography

\section{Availability of data and materials}

The datasets used and/or analyzed during the current study available from the corresponding author on reasonable request.

\section{Authors' contributions}

MNa collected and analyzed the data and draft the manuscript. KM conceived the study and edit the manuscript. YN collected the data and edit the manuscript. MNi analyzed the data and edit the manuscript. YKu analyzed the data. YKa, TK and MK edit the manuscript. NS supervised this work. All authors have read and approved the final manuscript.

\section{Ethics approval and consent to participate}

The present study was approved by the Institutional Review Board of Hokkaido University Hospital and the necessity to obtain written consent was waived because of its retrospective nature. Administrative permissions were received from the Institutional Review Board of Hokkaido University Hospital for accessing medical records in this study. (Approval number: 016-0095).

\section{Competing interests}

The authors declare that they have no competing interests.

\section{Publisher's Note}

Springer Nature remains neutral with regard to jurisdictional claims in published maps and institutional affiliations.

\section{Author details}

${ }^{1}$ Department of Renal and Genitourinary Surgery, Hokkaido University Graduate School of Medicine, North-15, West-7, Kita-Ku, Sapporo 060-8638, Japan. ${ }^{2}$ Diagnostic Center for Sonography, Hokkaido University Hospital, Sapporo, Japan. ${ }^{3}$ Division of Laboratory and Transfusion Medicine, Hokkaido University Hospital, Sapporo, Japan.

Received: 10 September 2017 Accepted: 18 May 2018 Published online: 29 May 2018

\section{References}

1. Levitt SB, Reda EF. Hypospadias. Pediatr Ann. 1988;17(1):48-9. 53-44, 57

2. Springer $A$, van den Heijkant M, Baumann S. Worldwide prevalence of hypospadias. J Pediatr Urol. 2016;12(3):152.e151-7.

3. Marrocco G, Grammatico P, Vallasciani S, Gulia C, Zangari A, Marrocco F, Bateni ZH, Porrello A, Piergentili R. Environmental, parental and gestational factors that influence the occurrence of hypospadias in male patients. J Pediatr Urol. 2015;11(1):12-9.

4. Skakkebaek NE, Rajpert-De Meyts E, Main KM. Testicular dysgenesis syndrome: an increasingly common developmental disorder with environmental aspects. Hum Reprod. 2001;16(5):972-8.

5. Wohlfahrt-Veje C, Main KM, Skakkebaek NE. Testicular dysgenesis syndrome: foetal origin of adult reproductive problems. Clin Endocrinol. 2009;71(4):459-65.

6. Moriya K, Mitsui T, Tanaka H, Nakamura M, Nonomura K. Long-term outcome of pituitary-gonadal axis and gonadal growth in patients with hypospadias at puberty. J Urol. 2010;184(4 Suppl):1610-4

7. Iwatsuki S, Kojima Y, Mizuno K, Kamisawa H, Umemoto Y, Sasaki S, Kohri K, Hayashi Y. Endocrine assessment of prepubertal boys with a history of cryptorchidism and/or hypospadias: a pilot study. J Urol. 2011;185(6 Suppl): 2444-50.

8. Nonomura K, Fujieda K, Sakakibara N, Terasawa K, Matsuno T, Matsuura N, Koyanagi T. Pituitary and gonadal function in prepubertal boys with hypospadias. J Urol. 1984;132(3):595-8.

9. Rey RA, Codner E, Iniguez G, Bedecarras P, Trigo R, Okuma C, Gottlieb S, Bergada I, Campo SM, Cassorla FG. Low risk of impaired testicular Sertoli and Leydig cell functions in boys with isolated hypospadias. J Clin Endocrinol Metab. 2005;90(11):6035-40.

10. Shima H, Ikoma F, Yabumoto H, Mori M, Satoh Y, Terakawa T, Fukuchi M. Gonadotropin and testosterone response in prepubertal boys with hypospadias. J Urol. 1986;135(3):539-42.

11. Backus ML, Mack LA, Middleton WD, King BF, Winter TC, True LD. Testicular microlithiasis: imaging appearances and pathologic correlation. Radiol. 1994; 192(3):781-5.

12. Drut R, Drut RM. Testicular microlithiasis: histologic and immunohistochemical findings in 11 pediatric cases. Pediatr Dev Pathol. 2002;5(6):544-50.

13. Shanmugasundaram R, Singh JC, Kekre NS. Testicular microlithiasis: is there an agreed protocol? Indian J Urol. 2007;23(3):234-9.

14. Meissner A, Mamoulakis C, de la Rosette JJ, Pes MP. Clinical update on testicular microlithiasis. Curr Opin Urol. 2009;19(6):615-8.

15. Sakamoto H, Shichizyou T, Saito K, Okumura T, Ogawa Y, Yoshida H, Kushima M. Testicular microlithiasis identified ultrasonographically in Japanese adult patients: prevalence and associated conditions. Urology. 2006:68(3):636-41.

16. Goede J, Weijerman ME, Broers CJ, de Winter JP, Van der Voort-Doedens LM, Hack WW. Testicular volume and testicular microlithiasis in boys with Down syndrome. J Urol. 2012;187(3):1012-7. 
17. Rocher L, Moya L, Correas JM, Mutuon P, Ferlicot S, Young J, Izard V, Benoit G, Brailly-Tabard S, Bellin MF. Testis ultrasound in Klinefelter syndrome infertile men: making the diagnosis and avoiding inappropriate management. Abdom Radiol (NY). 2016:41(8):1596-603.

18. Wasniewska M, Matarazzo P, Weber G, Russo G, Zampolli M, Salzano G, Zirilli G, Bertelloni S. Function ISGfAoGaP: clinical presentation of McCune-Albright syndrome in males. J Pediatr Endocrinol Metab. 2006;19(Suppl 2):619-22.

19. Richenberg J, Belfield J, Ramchandani P, Rocher L, Freeman S, Tsili AC, Cuthbert F, Studniarek M, Bertolotto M, Turgut AT, et al. Testicular microlithiasis imaging and follow-up: guidelines of the ESUR scrotal imaging subcommittee. Eur Radiol. 2015;25(2):323-30.

20. Nishimura Y, Moriya K, Nakamura M, Nishida M, Sato M, Kudo Y, Omotehara S, Iwai T, Wakabayashi Y, Kanno Y, et al. Prevalence and chronological changes of testicular Microlithiasis in isolated congenital undescended testes operated on at less than 3 years of age. Urology. 2017;109:159-64.

21. Asklund C, Jensen TK, Main KM, Sobotka T, Skakkebaek NE, Jorgensen N. Semen quality, reproductive hormones and fertility of men operated for hypospadias. Int J Androl. 2010;33(1):80-7.

22. Koyanagi T, Nonomura K, Yamashita T, Kanagawa K, Kakizaki H. One-stage repair of hypospadias: is there no simple method universally applicable to all types of hypospadias? J Urol. 1994;152(4):1232-7.

23. Goede J, Hack WW, Van der Voort-Doedens LM, Sijstermans K, Pierik FH. Prevalence of testicular microlithiasis in asymptomatic males 0 to 19 years old. J Urol. 2009;182(4):1516-20.

24. Peterson AC, Bauman JM, Light DE, McMann LP, Costabile RA. The prevalence of testicular microlithiasis in an asymptomatic population of men 18 to 35 years old. J Urol. 2001;166(6):2061-4.

25. Serter $\mathrm{S}$, Gümüş B, Unlü M, Tunçyürek O, Tarhan S, Ayyildiz V, Pabuscu Y. Prevalence of testicular microlithiasis in an asymptomatic population. Scand J Urol Nephrol. 2006;40(3):212-4.

26. Aizenstein RI, DiDomenico D, Wilbur AC, O'Neil HK. Testicular microlithiasis: association with male infertility. J Clin Ultrasound. 1998;26(4):195-8.

27. Thomas K, Wood SJ, Thompson AJ, Pilling D, Lewis-Jones DI. The incidence and significance of testicular microlithiasis in a subfertile population. $\mathrm{Br} J$ Radiol. 2000;73(869):494-7.

28. Xu C, Liu M, Zhang FF, Liu JL, Jiang XZ, Teng JB, Xuan XJ, Ma JL. The association between testicular microlithiasis and semen parameters in Chinese adult men with fertility intention: experience of 226 cases. Urology. 2014;84(4):815-20.

29. Miller FN, Sidhu PS. Does testicular microlithiasis matter? A review. Clin Radiol. 2002;57(10):883-90

30. Richenberg J, Brejt N. Testicular microlithiasis: is there a need for surveillance in the absence of other risk factors? Eur Radiol. 2012;22(11):2540-6.

31. Suominen JS, Jawaid WB, Losty PD. Testicular microlithiasis and associated testicular malignancies in childhood: a systematic review. Pediatr Blood Cancer. 2015;62(3):385-8

32. Møller $\mathrm{H}$, Cortes D, Engholm G, Thorup J. Risk of testicular cancer with cryptorchidism and with testicular biopsy: cohort study. BMJ. 1998; 317(7160):729

\section{Ready to submit your research? Choose BMC and benefit from:}

- fast, convenient online submission

- thorough peer review by experienced researchers in your field

- rapid publication on acceptance

- support for research data, including large and complex data types

- gold Open Access which fosters wider collaboration and increased citations - maximum visibility for your research: over $100 \mathrm{M}$ website views per year

At BMC, research is always in progress.

Learn more biomedcentral.com/submissions 